\title{
Nuclear Challenges to India's Security and its Response Strategy
}

\author{
Manpreet Sethi*
}

\section{Abstract}

This article analyses the three kinds of nuclear threats that India faces; Pakistan, China and nuclear terrorism. To counter Pakistan's nuclear threat against India's conventional military superiority, India's strategy has been assured retaliation in response to a 'first use', irrespective of its yield or choice of target. Though, China's nuclear strategy is against the United States, it poses a considerable security threat to India. India has acquired a nuclear triad to be able to mount an effective second strike capability, reaching almost all the cities of China. To counter nuclear terrorism, India collaborates internationally to counter such challenges.

Keywords: Nuclear Strategy, Territorial Disputes, Nuclear Terrorism

\section{Introduction}

India's nuclear challenges are unique in many ways. India seeks a workable deterrent strategy against two nuclear powers with different nuclear doctrines and capabilities. In fact, the nuclear situation for India is a complex web of diverse strategic relationships since its two nuclear-armed adversaries also share a robust nuclear and missile proliferation relationship between themselves. India shares not only contested borders but also

* Senior Fellow and Head of Nuclear Security, Centre for Air Power Studies, New Delhi, India; manpreetsethi07@gmail.com 
territorial disputes with both these countries; a reality that make border skirmishes a routine affair. While immense literature from the Cold War years is available on nuclear deterrence, most of it pertains to a bipolar nuclear confrontation between nations that were geographically distant. Much of this cannot apply to India given the nuclear 'tri-lemma' that it faces with contiguous nations. Therefore, India must necessarily find its own way to address its nuclear challenges.

Besides the nuclear challenges from Pakistan and China in the context of their changing nuclear and missile capabilities, India also faces a third challenge-nuclear terrorism. The paper is divided into three sections, each of which examines the three threats and offers an optimal Indian response at the doctrinal, capability build up and signaling levels.

\section{The Challenge from Pakistan's Nuclear Strategy}

Pakistan has a well-thought out and intelligent nuclear strategy that optimally fulfils the role for which it acquired nuclear weapons. Its nuclear strategy is solely focussed on deterring India. However, its nuclear weapons intend not to deter the nuclear weapons of India but the possibility of a conventional engagement with a superior Indian military; a possibility which it fears could arise as a result of its pursuit of terrorism. Terrorism has been a critical tool for the Pakistan foreign policy in order to keep India unsettled and to gain parity.

The acquisition of nuclear weapons has further lent support to this strategy by supposedly liberating Pakistan of the fear of any punitive response from India owing to the possibility of a nuclear escalation. Therefore, Pakistan's nuclear strategy is premised on augmenting these fears by projecting an immediate and inevitable escalation to the nuclear level in case of a conventional conflict. It is done to evoke fear not only to deter India but also to scare the international audience by playing up the possibility of a nuclear exchange between the two nations. Therefore, Pakistan communicates an inevitability of its nuclear use, however irrational, in order to establish deterrence with India. 
Projecting a low nuclear threshold, Pakistan has naturally opted for a nuclear strategy of using nuclear weapons against an Indian conventional strike. In order to make this look credible, Pakistan is reportedly adding rapidly to its nuclear warheads as well as fissile material and is also undertaking tests of delivery systems of the very short-range variety. Hatf IX or Nasr, a claimed nuclearcapable missile, with a range of no more than $60 \mathrm{kms}$ has been explained as a measure "to add deterrence value to Pakistan's strategic weapons development programme at shorter ranges" (ISPR, The Tribune, 2011). Obviously, such a system could only be a battlefield weapon and many strategic analysts in Pakistan and in the U.S have described it as a measure of countering a threat. Such attacks with low yield nuclear weapons on military targets could be to shock, create a sense of further danger, signal determination to intimidate India and to hinder its conventional operations. Furthermore, it also aims to get the international community to intervene and pressurise India against a nuclear retaliation.

While these motivations are quite understandable, the folly of undertaking such use of nuclear weapons cannot be lost on Rawalpindi either. A first strike/use strategy poses many challenges in execution. Pakistan might like to project that such first use with a battlefield nuclear weapon would be able to control the adversary's threshold of retaliation by coercing India to terminate the war and by not causing damage large enough to justify nuclear retaliation. Therefore, Pakistan assumes that its use of tactical nuclear weapons (TNW) would have simultaneously performed the tasks of retaining the upper hand on the use of nuclear weapons to bring about war termination while also ensuring damage limitation to its own territory. In fact, in such a conceived use of the nuclear tipped missile, its military effectiveness may be of little importance to Pakistan. The message they would be seeking to send through the game of brinkmanship would be targeted fully and completely at the political level. Therefore, the purpose of introducing nuclear weapons would certainly not be to redress balance on the battlefield but to make war too painful or too dangerous to continue by suggesting an expanding exchange of violence inflicted by the small yield weapon. Also, as stated earlier, a second assumption would be that 
the international community would stop India from nuclear retaliation.

Each one of these assumptions, however, could prove to be wrong. The behaviour of India and the international community after the use of a nuclear weapon, irrespective of the target and the yield of the weapon, or even the extent of damage suffered, could turn out to be completely contrary to Pakistani assumptions. Given that nuclear weapons have not been used in the last seven decades, a nuclear taboo against their use exists. Therefore, the use of a nuclear weapon would have strategic implications beyond IndiaPakistan and no leader deciding on such a use could take it lightly. That said, India cannot depend solely on the taboo alone to weigh in on Pakistan's calculations. Its own deterrent strategy must be credible and effective too. So, what should be India's response to Pakistan's nuclear strategy?

\section{India's Response to the Nuclear Challenge from Pakistan}

There appears to be little need for India to change either its nuclear doctrine or nuclear arsenal specific to moves such as Pakistan's TNW. India's approach to nuclear weapons has been categorical in maintaining that it has no interest in nuclear war fighting whether with small yield weapons on the battlefield or with large bombs on cities. The purpose of the Indian nuclear weapon is narrow and limited to safeguarding the country against nuclear coercion, blackmail or its possible use. The path it has chosen to achieve this is through the suggestion of deterrence by punishment. This strategy seeks to deter nuclear use by conveying assured retaliation in response to a first use, irrespective of its yield or choice of target. India's response would be meant to cause unacceptable damage. In that sense, the threshold for Indian nuclear use is very clearly stated as any kind of first use "on Indian territory or on Indian forces anywhere" (Cabinet Committee, 2009). For India, therefore, any use of the nuclear weapon would have strategic implications and would invoke a punitive response. The focus of the Indian nuclear arsenal must continue to remain on ensuring credibility through survivability of reliable delivery systems to mount necessary retaliation. 
In twenty years of operationalisation of its nuclear arsenal, India does have enough deployed missiles to cater to any nuclear contingency emanating from Pakistan. Meanwhile, in order to counter Pakistan's nuclear strategy premised on brinkmanship, India would do well to conduct effective nuclear signalling. It is well known that credible nuclear deterrence is derived as much from capability as from communication of resolve to use that capability. It, therefore, rests on the removal of all doubt from the mind of the adversary that any misadventure by him would result in assured retaliation that would inflict unacceptable costs. The effective communication of strength of resolve can go a long way in addressing some of the assumptions that seem to be underpinning Pakistani moves.

Fortunately, communication of resolve can be displayed through a range of actions. In fact, the resolve does not have to be conveyed through a nuclear war. Rather, indications of resolve can be made evident in actions such as firmness in law, order enforcement on the domestic front, decisiveness in policy making, the pursuit of inter-state relations, zero tolerance for terrorism, and so on. India's lack of action to mete out punishment to Pakistan even after a series of acts of terrorism since 2007 had lent itself to the impression that the country had a weak resolve to retaliate. That changed in September 2016 when India publicly announced conducting surgical strikes against active terrorist launch pads in Pakistan. India's effort at diplomatically isolating Pakistan and publicly naming and shaming it as the mother-ship of terrorism also indicate India's intention of punishing future acts of terrorism emanating from Pakistan.

Therefore, in nuclear strategy, it is not essential to respond to every nuclear capability driven move of the adversary. While the developments certainly need to be monitored, the initiative must be retained by the self in terms of choosing an own response instead of automatically following the trends set in motion by the other side. India is not interested in fighting a nuclear war, whether of the limited and tactical variety or a larger strategic exchange. In fact, for enhancing India's nuclear deterrent with respect to Pakistan, it is necessary to undertake manipulation of perceptions on India's willingness to take necessary actions to handle 
deterrence breakdown. According to an analyst, "It makes no sense to surprise an opponent with unanticipated retaliation when a clear signal could have deterred unwanted activity in the first place" (Wirtz, 2012). Building nuclear capability is meaningless if the adversary does not know about it, misreads it, or if he doubts the resolve to put it to use. It is critical, therefore, to convey a coherent and consistent message so that the adversary does not premise his own nuclear strategy on mistaken assumptions. This is the aspect that needs to be emphasized in order to address the nuclear challenge posed by Pakistan's nuclear strategy.

\section{The Challenge from China's Nuclear Modernisation}

China has been steadily modernising its strategic capabilities over the last three decades. Clearly, Chinese nuclear hardware - its nuclear weapons and delivery capabilities - have steadily undergone an upgradation. This has been enabled by the country's sustained economic growth and consequent liberal spending on military modernisation. It is being justified by the changes in the country's threat perceptions arising from the prospect of the deployment of ballistic missile defence (BMD) by the USA. Of particular concern to China is the deployment of Theatre Missile Defence (TMD) over Taiwan that could jeopardize China's reunification policy.

As a result of these developments, China is engaged in a rapid but intelligent nuclear modernisation. It is choosing capabilities after a careful consideration of the vulnerabilities of the USA. Though China remains absolutely opaque on the number of its nuclear warheads except to state that it has the smallest arsenal among all the five nuclear weapon states (NWS), estimates about its nuclear numbers vary from 200 to 450 . But these figures are essentially guesstimates; neither confirmed nor denied by China's officialdom. Given that it seeks to deter through the threat of its ability to cause 'unacceptable damage', the focus of Chinese efforts has been to build capabilities that can assure such damage. Accordingly, China has made progress in improving missile capabilities. Particular attention can be seen towards developing measures that can assure survivability of missiles since China subscribes to the doctrine of no first use of nuclear weapons. The credibility of its deterrence is 
therefore dependent on being able to inflict such damage even after taking the first strike on itself.

Consequently, China has placed greater emphasis on increasing the numbers, reliability, accuracy and mobility of its missiles. It has been engaged in building more solid-fuelled, rail and road-mobile missiles. Further, realising the vulnerability of land-based missiles despite the best survivability measures, the spotlight has been on making sea-based deterrence capability operational. A Chinese Admiral, Liu Huaqing, had highlighted this emphasis in the 1990s when he stated, "In the face of a large-scale nuclear attack, only less than 10 per cent of the coastal launching silos will survive, whereas submarines armed with ballistic missiles can use the surface of the sea to protect and cover themselves, preserve the nuclear offensive force and play a deterrent and containment role."(Ji, 1999) The sea leg of the Chinese nuclear triad rests on Julang 2 (JL-2), a second generation submarine-launched a ballistic missile (SLBM) of a little over $7000 \mathrm{~km}$ range that would be deployed on indigenous Type 094 submarines. These Jin class SSBNs (some currently without the missile component that is still under trials for greater reliability and accuracy) have reportedly started undertaking sea patrols since 2015 (Shim, 2015).

Meanwhile, though air delivery was the first capability available with China after it developed nuclear weapons, this remained a weak arm, given the short-range of aircrafts and their inability to penetrate enemy air defences. But, China has changed the situation by inducting $\mathrm{H}-6 \mathrm{~K}$ bombers fitted with engines of greater thrust power and reinforced fuselage structure. Armed with dual use, long-range cruise missiles of a range of $2,500 \mathrm{kms}$, the $\mathrm{H}-6 \mathrm{~K}$, even if a subsonic bomber, is now believed to have the operational capability to effectively project nuclear deterrence (Chang, 2007).

With the American BMD in mind, China has invested heavily in developing technical counter-measures such as the use of chaff, decoys, balloons, and stealth technologies. More significantly, China has worked on making its missiles equipped with multiple independently retargetable vehicles/warheads (MIRVs) (Yomiuri Shimbun, 2003). China is known to have been miniaturising warheads to make them lighter and easier to deploy in multiple numbers ranging from 3-10 atop its delivery systems (Gertz, 2016). 
Secondly, Beijing has also developed the capability to make the reentry of its nuclear warhead manoeuvrable (MARVed missiles) thereby making it difficult to intercept.

A lot of new technologies will be dependent on space-based capabilities and China is rapidly modernising these both for offensive and defensive operations. Beijing's demonstration of an anti-satellite (ASAT) capability in 2007 came from the determination that a robust ASAT capability could counter the USA by disabling the "complex, exposed network of command, control, communications, and computer-based systems that provide intelligence [and] reconnaissance" to American forces. ${ }^{\mathrm{i}}$ Indeed, Chinese defence planners see the networked nature of American forces as their principal vulnerability. China's endeavour is to develop capabilities that could blind US sensory and networking organs (surveillance, reconnaissance and intelligence assets in space) and it appears to be pursuing this in a determined fashion through the development of a range of technologies including directed energy weapons and electronic attacks through sophisticated jamming technologies.

It is apparent that China is moving up to a higher level of strategic capability. In fact, while earlier, its nuclear deterrence was largely based on ambiguity and secrecy in numbers and capability, it is now being derived from mobility, invulnerability and penetrability of its nuclear delivery systems. However, this need not automatically lead to the conclusion that China would be keen to engage in nuclear war-fighting. Rather, it is likely to use the transparency it has allowed about the development of these capabilities to further the deterrent value of its nuclear weapons. This capability enhancement and its concomitant impact on deterrence are primarily meant for the USA. But it obviously has a downstream effect on its deterrent equation with India too. So, how should India look at these developments of Chinese strategic modernisation and what responses should it focus on?

\section{India's Response to the Nuclear Challenge from China}

The implications of China's nuclear modernisation for India arise more from having to face the prospect of a more assertive China in 
the coming years. Certainly, with a rise in its perception of comprehensive national power (nuclear capability being one component), China does believe it carries more weight today. This gives it the confidence to actively participate in the international rule-making or rule breaking with impunity; aspects that India must watch out for. China respects strength and hence India must focus on building capability that communicates its nuclear strength in order to address the challenge posed by China's strategic modernisation.

Amongst the technological advancements that India must focus on after having developed and deployed a number of land-based ballistic missiles, (including the Agni variants that are solid-fuelled missiles and rail and road mobile) are the long-range, canisterised Agni V missiles. These are currently in a process of being tested so as to be ready for operational induction. Another urgent pending task is the true operationalisation of the sea-based leg of India's nuclear triad. The recent commissioning of INS Arihant, India's indigenous SSBN, has marked the initiation of the journey. But an operational, credible sea-based deterrence requires a fleet of at least 4-5 SSBNs. These can then provide a higher level of survivability particularly if future boats carry SLBMs of longer ranges. What has been tested until now are the K-15 with a range of $700-750 \mathrm{kms}$ and the K-4 with a range of 2000-2500 kms (Times of India, 2014). These ranges are insufficient for credible deterrence against China. The missiles have to go up to a range of at least $5000 \mathrm{kms}$ and more to reach targets whose loss would be deemed unacceptable by Beijing while themselves remaining far away from the adversary. Thirdly, the focus must be retained on improving the penetrability of Indian missiles. Fortunately, China's BMD is still of limited capability. But, Indian missiles will have to be equipped with increasingly sophisticated counter-measures to evade interception in order to convey the capacity to cause unacceptable damage. Therefore, development of multiple re-entry vehicles (MRVs), which hit the same target with many bombs, and manoeuvrable reentry vehicles (MaRV) that can drastically change trajectory to evade interception in the terminal stage, are capabilities that will help in buttressing deterrence. Meanwhile, MIRVed missiles have essentially been considered first strike weapons and do not really find a place in India's NFU strategy. However, given the trend 
towards this development in the region, India would be prudent to keep options open while it focusses on other more urgent tasks towards enhancing the credibility of deterrence.

This implies that while mere numbers and balance of force might not be relevant because the scale of destruction caused by even a few nuclear weapons could constitute unacceptable damage, what is critical is to ensure that sufficient warheads and delivery vehicles survive a first strikeii and be ready for retaliation. This calls for the creation of a secure second-strike potential in the form of hardened silos, mobile launchers, deployment beyond the reach of hostile delivery systems, dispersion of the arsenal on a triad, and structured weapon release authority in order to guarantee an assured appropriate response. Reliability of the delivery system is critical for deterrence credibility and this includes dependability of communication (that the correct message is delivered at the right time for launch); of launch (that the missile actually lifts off); of the booster (that it ignites in time); of separation (of the booster from the missile after burn out); of penetration (despite enemy air defence systems); and of detonation (at the designated target).

A robust Command, Control, Communication and Intelligence systems (C3I) is also critical to ensure that the nuclear assets remain secure in peacetime but can make the shift to fully employable forces when necessary in the shortest possible time for effective retaliation. Such a system comprises personnel, procedures that acquire, collate, analyse and interpret information to assist decision making and equipment that enables acquisition and transmission of decisions to different constituents of the force in real time. Effective surveillance and early warning capabilities to acquire intelligence on adversary's force posture is also necessary to minimise risks of a miscalculated or inadvertent strike based on faulty intelligence or false alarms.

\section{The Challenge of Nuclear Terrorism}

The term nuclear terrorism generally encompasses three kinds of actions by non-state actors. These include the use of a readymade nuclear weapon from an existing national nuclear arsenal by a nonstate actor; an act of sabotage of a nuclear facility that contains 
fissile/radiological material or the use of radiological dispersal devices or dirty bombs. Of the three, the possibility of the first kind of nuclear terrorism is the most difficult given that nuclear weapons in national arsenals are well accounted for and protected. Theft or pilferage of whole nuclear weapons, including delivery systems and knowledge of electronic codes to launch them, cannot be an easy task for any terrorist organisation unless of course, there is state complicity in such an activity. The second act of sabotage is relatively difficult to envisage given that nations with nuclear facilities are sensitive to nuclear safety and security requirements necessary to keep them from harm's way. However, the last kind of activity could be the most worrisome given that such devices can be crafted with little quantities of nuclear or radiological material along with conventional explosives. This could be possible if the terrorist could lay his hands on enough nuclear/radiological material through theft, purchase on the illicit market, or insider cooperation from an employee at a nuclear facility.

Crafting a dirty bomb is also perfectly possible by mixing high explosives with relatively long-lived radioactive isotopes such as cesium 137, strontium 90, or cobalt 60 which are found in places other than nuclear establishments. Most of these are available at universities, hospitals and industries that may be less secure than nuclear facilities. For instance, Cobalt 60 is used to sterilise surgical instruments, in cancer treatment, food irradiation, gauges, and radiography as well as to improve the safety and reliability of industrial fuel oil burners. Similarly, strontium 90 is used in survey meters by schools, the military and emergency management authorities, as also in cigarette manufacturing sensors and for medical treatment.

Given the relatively easy portability of radiological materials, lax security at sites where they are used and the likelihood of some of these sources being orphaned or casually discarded over time, RDDs are far easier to construct, conceal or detonate by terrorists than the first case of their use of a nuclear weapon. An RDD may also be perceived as being more useful to terrorise rather than kill too many people since the impact of such an incident would be more in terms of creating economic problems, logistic disruptions and psychological panic among the people. The chaos so created 
might serve the interest of the terrorists more than causing mass deaths and the resultant revulsion.

The possibility of such a terrorist act being mounted against India is not all that remote. It is surprising that despite being a victim of terrorism for decades and despite the entry of nuclear weapons into the region (particularly in Pakistan which has a penchant for use of terrorism), India has never articulated an official policy towards the use of RDD. In fact, there does not exist any detailed official assessment of the threat (at least not in the public domain). The situation is further exacerbated when one realises that Pakistan may not exercise complete control over the myriad militant organisations that it has supported over time. A scholar who has been a keen Pakistan watcher, Christine Fair, has provided a good sense of the picture that she obtains in Pakistan when she candidly admits, "Despite its seeming dedication to combating those elements of the TTP that target the state, Pakistan will likely remain unable or unwilling to eliminate even those groups, owing to the overlapping membership between the vehemently anti-state components of the TTP and Deobandi groups that Pakistan still views as assets as well as to Islamabad's fear that its militant proxies will be crucial allies in any future war against India" (Fair, 2014). In addition, in his testimony to the House Committee on Homeland Security, Steve Coll, President of New America Foundation stated, "having nurtured Islamist groups..., Pakistan has been weakened by their virulence and revolutionary ambition, and the state now lacks the capacity to wipe out the groups without paying a very high price and incurring great risks..." (Coll, 2011). Many splinter groups have appeared in recent times and many of these are known to be against their own establishment. Given many such groups, including the Pakistani Taliban that is waging an insurgency against the country, the chances of "a splinter group armed with nuclear expertise and access from within the Pakistani establishment looks increasingly feasible" (Coll, 2011). So, how should India handle this threat?

\section{India's Response to the Challenge of Nuclear Terrorism}

India has enthusiastically joined international attempts aimed at addressing the threat of nuclear terrorism. It is a member of nearly 
all the international treaties and conventions aimed at enhancing nuclear security. It has also participated actively with the IAEA in updating its guidelines and conducting international training courses on the physical protection of nuclear facilities and materials.

Meanwhile, within the country, Central Industrial Security Force (CISF) is entrusted with the task of security of these establishments and over the last years, the training and equipment of the personnel have been given special attention. Apart from that, the preparedness of India to handle nuclear terrorism traverses four main domains - legal provisions, surveillance and safety mechanisms, emergency response mechanisms and external collaboration. While elements of all the four domains are in place, one can never assert with any guarantee that the nation's nuclear security is perfect since it is heavily dependent on the international climate as well as the support, or lack of it, from other countries. In case of India, the enforcement of these measures by the countries in the region is of particular importance and it must do all it can to support their implementation in its neighbourhood nations through bilateral and international efforts, while effectively securing its own borders and improving its intelligence infrastructure and analysis capabilities.

\section{Conclusion}

In view of the varied and complex nuclear threats that India faces, its relevant strategy must be able to find the right approach to stabilise the situation with Pakistan while avoiding getting into a messy and expensive arms race with China. This requires staying focussed on certain necessary nuclear hardware while at the same time playing a sophisticated game of perception manipulation of the adversary.

India ascribes a narrow purpose to its nuclear weapons. These are considered a means of deterrence only against nuclear weapons of the adversary and to be used only for safeguarding oneself against nuclear blackmail or coercion. India rejects the concept of nuclear war-fighting. Protection of the country can only come from deterring the other's use of these weapons against oneself rather 
than using them against the adversary especially when he himself has a secure second-strike capability which is sure to bring retaliation upon oneself. By premising its nuclear strategy on such an understanding, India has freed itself from the need to build a large arsenal or to do it competitively with the adversary. Without mentioning numbers, the essential message has always been that the arsenal would be large enough to cause unacceptable damage (Sethi, 2016). But then, given the nature of the destructive potential of this weapon, not too many are needed in any case. Rather, what is necessary is the ability to project confidence in the capability to inflict damage that the adversary would find unbearable.

\section{References}

Chang, A. (2007). China Attains Aerial Nuclear Strategic Strike Capability. Retrieved from http://www.spacewar.com

Coll, S. (2011). Terrorist Safe Havens After Bin Laden: An AssessmentTestimony to the House Committee on Homeland Security, Subcommittee on Oversight, Investigations and Management. Retrieved from https://www.congress.gov/congressional-report/ 112th-congress/house-report/351/1

Fair, C. (2014). Fighting to the end: The Pakistan Army's way of war. New York: Oxford University Press.

Gertz, B. (2016). China flight tests new multiple-warhead missile. Retrieved from https://freebeacon.com/national-security/chinaflight-tests-multiple-warhead-missile/

ISPR. (The Tribune, April 20). Pak test fires nuclear capable hatf 9 missile. The Tribune.

Ji, Y. (1999). The Armed forces of China. Canberra: Allen \& Unwin.

Muradian, V. (2007). China's mystery satellites: US gauges Beijing's ASAT strategy. Defense News.

Sethi, M. (2016). Nuclear deterrence and India: doctrine, strategy, force structure and operationalisation. In G. Kanwal (Ed.), The New Arthashastra: A security strategy for India. New Delhi: Harper Collins.

Shim, E. (2015, October 1). China dispatched N-Powered submarine on first combat patrol, report says. Retrieved from https://www.upi.com/Top_News/World-News/2015/ 10/01/ China-dispatched-nuclear-powered-submarine-on-first-combatpatrol-report-says/1331443713383/ 
The Cabinet Committee. (2003, January 4/2009). The cabinet committee on security reviews operationalisation of India's nuclear doctrine. Reproduced in M. Sethi (Ed.), Nuclear strategy: India's march towards credible deterrence, pp. 347-348. New Delhi: Knowledge World.

Times of India. (2014, March 26). India tests new underwater nuclear missile. Retrieved from https://timesofindia.indiatimes.com/ india/ India-tests-new-underwater-nuclearmissile/articleshow/32694060.cms

Wirtz, J. J. (2012). Deterring the weak: problems and prospects. Proliferation Papers, IFRI Security Studies Centre. Retrieved from https://www.ifri.org/fr/publications/enotes/proliferationpapers/deterring-weak-problems-and-prospects

Yomiuri S. (2003, February 8). China successfully tests multi-warhead missiles. Yomiuri Shimbun. Retrieved from http://www.taiwansecurity.org/News/2003/YS-020803.htm

\section{End Notes}

i According to a report prepared by Michael Pillsbury for the US bipartisan China Economic and Security Review Commission that is based on writings of 20 Chinese military strategists, there are three books and several dozen articles going back a decade that advocate development of ASAT to covertly shoot down satellites to send a deterrent message (Muradian, 2007).

ii Technically, first strike is an attack so powerful so as to leave one's opponents with forces which are insufficient to inflict substantial damage on the attacker. 